\title{
A Educação no (Super) Mercado: 0 Conhecimento Vale O Quanto Pesa? Resultados da Política Neoliberal e a Ação Do Marketing Educacional
}

\section{Education in the (Super) Market: \\ Is Knowledge Worth How Much Weigh? Results of the Neoliberal Policy and the Action of Educational Marketing.}

\author{
AIRTON RODRIGUES ID \\ ADRIANA BARROSO DE AZEVEDO D
}

\section{RESUMO}

Este artigo propõe apresentar alguns aspectos sobre o atual momento da educação no Brasil, a qual vem atravessando profundas mudanças em virtude da política econômica neoliberal que afetou de forma bastante incisiva o modo como a educação tem sido oferecida aos alunos, em especial no ensino superior da rede privada. A mercantilização da educação nesse contexto em que o conhecimento tem sido considerado um produto, atua por meio do marketing educacional utilizando-se de todas as estratégias e táticas para efetivar a conquista do seu público alvo, assim se apresenta como objeto do desejo das grandes corporações educacionais: o futuro aluno. Por representarem de forma direta o sentido de um negócio lucrativo, observamos um cenário complexo no qual a comunicação no mercado educacional vem sendo aplicada como importante ferramenta por grandes corporações nacionais e internacionais que compõem agências publicitárias altamente especializadas na chamada "captação de alunos para instituições de ensino". Como base para reflexões, as análises serão elaboradas em estudos apresentados nas seguintes obras: 
"Comunicação para o mercado educacional" de Tório Barbosa1; "Dos passos estratégicos aos caminhos do marketing educacional" de Mekler Nichele Nunes ${ }^{2}$ e "A escola não é uma empresa: o neoliberalismo em ataque ao ensino público de Christian Laval ${ }^{3}$. Palavras-chave: Marketing educacional. Neoliberalismo na educação brasileira. Comunicação e mercado educacional.

\section{Abstract}

This article proposes to present some aspects about the current moment of education in Brazil, which has been going through profound changes due to the neoliberal economic policy that has affected in a very incisive way the way education has been offered to students, especially in higher education in Brazil. private network. The commodification of education in this context in which knowledge has been considered a product, operates through educational marketing using all strategies and tactics to achieve the conquest of its target audience, thus presenting itself as the object of the desire of large corporations educational: the future student. As they directly represent the meaning of a profitable business, we observe a complex scenario in which communication in the educational market has been applied as an important tool by large national and international corporations that make up advertising agencies highly specialized in the so-called "attracting students to educational institutions. teaching". As a basis for reflections, the analyzes will be elaborated in studies presented in the following works: "Communication for the educational market" by Tório Barbosa; "From the strategic steps to the paths of educational marketing" by Mekler Nichele Nunes and "The school is not a company: neoliberalism in attack on Christian Laval's public education.

Key-words: Educational Marketing. Neoliberalism in Brazilian Education. Communication and Educational Market.

1 Reconhecido como referência em captação de alunos no Brasil, foi fundador e CEO de uma das maiores e mais conceituadas agências de publicidade especializada em instituições de ensino do país. Atualmente é co-fundador da Mkt4edu, empresa especializada em captação de alunos com inovação e tecnologia.

2 Diretor Superintendente de Educação Básica na Pearson Brasil. É matemático, graduado em ciências Atuariais pela Faculdade de Economia e Finanças do Rio de Janeiro. Possui MBA em Gestão Empreendedora pela ESPM-SP e MBA em Direção Estratégica pelo ISAE/FGV.

3 Christian Laval é um pesquisador francês da história da filosofia e da sociologia na Universidade Paris Nanterre. Seus trabalhos centram-se em três grandes temas: a história do utilitarismo, a história da sociologia clássica e a evolução dos sistemas de ensino. 


\section{INTRODUÇÃo}

A educação sempre foi considerada um "bem" no qual seu valor, dentre as possíveis acepções utilizadas em nossa língua poderia ser representado no sentido de importância, relevância e mérito, mas quando nos referimos à educação superior do ensino privado nos dias atuais seu significado parece adquirir outra possibilidade, qual seja o preço que se paga ou se recebe por alguma coisa.

Trazendo um pouco do contexto histórico, apontamos o registro do neoliberalismo econômico no Brasil que teve seu início com o governo do presidente Fernando Collor de Mello em 1990 e se consolidou com a chegada de Fernando Henrique Cardoso à presidência da república em 1995. Esse movimento representou profundas mudanças no ordenamento econômico do país, o qual suscitava como bandeira a promessa, dentre tantas, a de propiciar maior acesso a benefícios por parte da população e de liberdade de mercado com a livre concorrência.

Essa opção política possibilitaria ao país e aos seus cidadãos uma melhor condição de vida, já que dentre seus pressupostos, uma economia aberta e concorrencial objetiva, além de redução de custos nos serviços antes prestados somente pelo Estado - carregado por custos elevados com a manutenção da máquina estatal -, o consequente acesso desses mesmos serviços a um número maior da população.

O que a princípio pode nos levar à compreensão de que seria uma política facilitadora no sentido de oferecer condições mais igualitárias às camadas economicamente mais afetadas em nossa sociedade.

Dentre todos os serviços obrigatórios que o Estado oferece à população, temos na educação o que poderíamos chamar de "bem maior", preconizada em nossa Constituição Federal de 1988 no artigo $205^{5}$ como: "dever do estado, direito de todos".

Assim nessa lógica, o Estado teria em tese, mais atenção e recursos para investir nos três principais serviços públicos sempre presentes em qualquer discurso de um candidato a cargos do poder executivo: educação, segurança e saúde.

Art. 205. A educação, direito de todos e dever do Estado e da família, será promovida e incentivada com a colaboração da sociedade, visando ao pleno desenvolvimento da pessoa, seu preparo para o exercício da cidadania e sua qualificação para o trabalho. (grifo nosso). 
Na presente reflexão procuro me ater à educação e como ela teve de modo muito significativo dentro de uma política neoliberal um processo inverso em relação ao que diz respeito a investimentos e ampliação desse direito. Como bem descreve Aguillar (2000 in Tavares, 2012, p.84) quando demonstra que:

O Estado passa a adotar nas novas políticas um ethos competitivo que inclui premissas de resultados, sistemas, regulação e não mais de execução. Sai de cena gradualmente o Extado-executor de políticas públicas no ensino superior, assumindo em seu lugar o Estado-regulador e o Estado-avaliador. No fundo é um Estado-desertor.

Como resultado, o Estado-desertor abriu caminho para as instituições privadas de ensino superior e de uma oportunidade sem precedentes em conquistar um público até então impossibilitado de frequentar as Universidades Públicas, sejam Federais, Estaduais ou Municipais, considerando apenas a relação demanda e oferta da educação existente até então.

Para a população de um modo geral, principalmente as camadas menos favorecidas da sociedade, a abertura de grandes corporações de ensino superior representou nesse primeiro momento a possibilidade real de acesso ao ensino do terceiro grau, o que até então era para uma parcela significativa da sociedade muito difícil de se alcançar, ou seja, o sonho de chegar a uma universidade.

Assim, considerando uma demanda volumosa em números de possíveis estudantes que rapidamente foram compreendidos como "clientes", o passo seguinte observado pelas grandes corporações de ensino ficou no âmbito de promover a "conquista do aluno". E para isso lançaram mão dos recursos mais eficazes e efetivos para alcançar esse objetivo, qual seja, a utilização do Marketing Educacional.

Desse modo se fez necessário que essas corporações efetivassem a contratação de renomadas agências de publicidade altamente especializadas em "vender" a instituição de ensino como sendo cada uma a melhor opção dentre suas concorrentes.

E para entendermos como o marketing educacional se efetiva e executa suas funções e quais atribuições são a ele entregues com 
o intuito de que, com efeito, alcancem seus objetivos, Nunes, (2014, p.280) nos explica que:

O marketing, mesmo o educacional, só atinge sua plena efetividade se desenvolvido a partir de uma perspectiva estratégica bem delineada que o condiciona e que, a partir dele, condicionará seus esforços, seus projetos e seu curso de ação. Perguntas sobre infraestrutura, mercado competitivo, portfólio, públicos-alvo, efeitos regulatórios, níveis de investimento ou perfil tecnológico dos serviços requerem respostas prévias à ação de marketing de uma instituição de ensino(...).

Desse modo, podemos agora adentrar no universo publicitário e compreender seus meandros e de como tem sido amplamente utilizado na busca e conquista por alunos para se tornarem consumidores de educação e conhecimento, cenário que foi propiciado pela política econômica neoliberal em que o Estado abandona seu papel de gestor e facilitador de acesso ao ensino superior e transfere de forma implícita à iniciativa privada essa prerrogativa.

\section{A GRANDE CHANCE: UMA POSSIBILIDADE PARA CURSAR O ENSI- NO SUPERIOR.}

Esta afirmação certamente fora a mais comemorada e desejada por um grupo social no qual o acesso ao ensino superior sempre foi algo semelhante a um sonho impossível. O ensino público tão rechaçado nas etapas iniciais da educação e até mesmo nos níveis fundamental e médio por uma parcela significativa da população, tem no ensino superior um sentimento inverso.

O desejo por um ensino de qualidade e gratuito garantido em nossa constituição federal, ganha no ensino superior, com uma representação social a garantia de um futuro promissor a quem alcança essa conquista.

Mas a relação demanda versus disponibilidade tem uma matemática com resultado cruel. A constituição preconiza o oferecimento, mas o Estado não disponibiliza vagas, assim o acesso às universidades públicas passa de sonho a pesadelo, e o pior, representa em muitos casos a desistência do aluno em seguir uma vida acadêmica. 
Nesse contexto, as IES privadas surgem como a fada madrinha realizadora dos desejos impossíveis, aqueles a quem as condições sociais e econômicas não possibilitaram a oportunidade de estarem inseridos em uma universidade pública agora podem enfim, cursar o ensino superior. Mas como fazer chegar a esse futuro estudante as informações necessárias para que ele acredite nessa possibilidade?

Para responder a esta pergunta, entram em cena as agências especializadas em marketing educacional. Utilizando todos os recursos humanos e tecnológicos possíveis aplicados à conquista de um cliente, unem-se como prestadoras de serviços às instituições privadas para criar mecanismos captadores de futuros estudantes com objetivo específico de conquistar a tão desejada matrícula do aluno.

Como sequência lógica nesse caminho uma primeira percepção das agências foi a necessidade de identificar quais características são importantes para que um futuro aluno escolha uma ou outra IES $^{6}$, mais do que isso, procurou-se entender se esse futuro aluno compartilha com seu grupo "rede" sobre seus anseios quando tem interesse em ingressar no ensino superior.

O marketing como já mencionado, seja educacional ou não, tem como ação inicial para qualquer projeto publicitário a realização de questionários dirigidos ao público alvo do produto que se quer oferecer, para que por meio das respostas emerjam quais são os critérios considerados pelo "cliente" em relação ao produto ou serviço desejado.

Assim como respostas resultantes das pesquisas, a primeira constatação foi de que um aluno não decide sozinho pela escolha da IES, como nos demonstra Barbosa.

"No mercado educacional, quando um estudante decide por uma IES, ele conversa com parentes, pais, professores de ensino médio e de pré- vestibulares, namorado ou namorada ou um conhecido que frequente uma IES. Na verdade, quem escolhe não é ele, mas a rede social da qual faz parte(...). (Barbosa, 2011, p.301).

Instituições de Ensino Superior. (Confessionais, Faculdades, Centros Universitários, Particulares) 
Diante dessa constatação, o passo seguinte é buscar nesse grupo social, hoje denominado "rede", o que são considerados pontos relevantes para a escolha de uma instituição de ensino. O que esse aluno espera? É de extrema importância para o marketing educacional compreender nos futuros alunos os seus sentimentos, desejos, expectativas desde as análises que são feitas sobre a estrutura física da instituição até as questões relacionadas ao curso no qual pretende ingressar.

Uma vez compreendido que o ensino seria considerado como um "serviço" a ser prestado pela IES privada ao aluno, e de um entendimento sobre quais critérios esses alunos consideram importantes para decidirem em qual delas querem estar vinculados, o próximo passo é fazer com que o futuro aluno veja na instituição " $\mathrm{A}$ " seus ideais atendidos em detrimento da instituição " $\mathrm{B}$ ".

\section{COMUNiCAÇÃo NA REDE: A CHAVE do "NEGócio".}

As agências de publicidade sabem desde os primórdios que entre o produto e o cliente existe a necessidade de se estabelecer uma comunicação, e que esta esteja direcionada a fazer com que o primeiro atenda aos anseios do segundo, e é por meio da comunicação que esse elo se confirma.

Então, considerando hoje as tecnologias comunicacionais ${ }^{7} \mathrm{em}$ rede, observou-se por resultados obtidos pelas agências publicitárias que não só o futuro aluno seria alvo de ações de marketing no objetivo de conquistá-lo, mas também seria de grande importância reforçar ao aluno atual as boas qualidades da IES escolhida, pois ele também é fonte de divulgação de uma IES, quando se sente satisfeito com o "serviço" prestado. Isso fica demonstrado quando o autor nos explica que:

Se o aluno atual é o principal $h u b^{8}$ de uma rede de escolha de uma IES, é nele que a comunicação deve ser concentrada inicialmente. Tal compreensão muda muito à forma de como se deve pensar uma

7 Considera-se rede comunicacional para divulgação de produtos e serviços - Facebook -Waths-app - Instagran - Linkedin -Telegram.

8 Hub, palavra inglesa que significa Cubo. Utiliza-se no marketing educacional como um sinônimo de alvo, no caso da educação representa o aluno atual. 
campanha de vestibular, por exemplo, pois isso implica fazer a divulgação sempre pelos alunos atuais, e não pelos futuros alunos. (Barbosa, 2011, p.303).

Em sequência, as agências de marketing educacional, cientes da importância em manter o foco nas relações estabelecidas entre os alunos atuais como um dos "instrumentos" para a conquista de alunos novos, apresentaram como resultado de estudos uma lista de ferramentas possíveis consideradas mais relevantes, as quais favorecem a manutenção da satisfação que o estudante atual percebe e ainda o ajudam a manter seu desejo em permanecer na IES escolhida, afinal mais do que a matrícula, permanecer na instituição representa o objetivo mais importante.

Para uma melhor compreensão, as ações abaixo citadas são executadas no âmbito interno da IES, ou seja, se apresentam como uma publicidade para alunos matriculados, de valorização da IES para esse público, e ainda cabe esclarecer que não se torna necessariamente imprescindível que todas sejam utilizadas de modo simultâneo, conheçamos algumas:

- Revista científica - apresentando produções acadêmicas relevantes realizadas por alunos nas respectivas áreas do conhecimento;

- Revista de comportamento - cuidadosamente preparada e direcionada ao público específico da unidade escolar (contexto social da IES);

- Outdoor interno - fotos bem elaboradas que objetivam reforçar a imagem da IES, apresentando áreas de acolhimento e convivência;

Banners espalhados nas áreas de grande circulação, preferencialmente com alguns alunos da própria instituição atuando em laboratórios e bibliotecas (estes ambientes demonstram o potencial da instituição quando apresentam equipamentos avançados e estantes repletas de livros) as quais são utilizadas com a finalidade de incutir no aluno um sentimento de orgulho por fazer parte da IES.

Não é objeto de análise neste trabalho, mas creio seja importante esclarecer que as ações publicitárias até o presente momento discutidas e apresentadas, podem ser e normalmente o são, utilizadas em 
instituições Confessionais, onde o caráter da comunicação pode ou não ser voltado ao público cuja religião a IES confessa, bem como em Faculdades e Centros Universitários de maneira que cada instituição adeque a sua comunicação ao corpo discente em que nelas estejam inseridos.

- Podemos agora, diante do que até aqui fora apresentado ter uma noção mais clara de que a educação, especificamente no ensino superior privado, inserida numa política neoliberal, teve por partes das IES uma deferência sobre o "conhecimento" comparando- o a um "produto" vendido num supermercado, posto na prateleira, no qual o slogan ${ }^{9}$ deve proporcionar tanto ao aluno estudante o desejo de permanecer na instituição que frequenta como fazer dele um divulgador para novos e futuros alunos.

\section{A EduCaÇão Vale o QUANTO PESA?}

Apresentamos até agora algumas considerações sobre os aspectos comunicacionais os quais as IES privadas utilizam na captação de alunos, sabemos da forte concorrência existente entre as grandes empresas da educação e quais ferramentas, estratégias e práticas são utilizadas por elas na busca frenética por um aluno novo, afinal as instituições de ensino investem valores volumosos em instalações e precisam ter consumidores para seus produtos e que estes possam com o pagamento dos serviços prestados (mensalidades) arcarem com todas as despesas fixas e obviamente gerarem lucros.

Mas nesse percurso existiria por parte das IES a preocupação com a qualidade do ensino e um comprometimento social?

Visto que a elas são concedidos à possibilidade de prestarem um serviço do qual o Estado de forma velada terceirizou, mas que tem como finalidade precípua a formação de cidadãos críticos e conscientes da realidade em que estão inseridos e sabemos que a educação é o motor condutor que representa o avanço tão almejado em qualquer sociedade, essa é uma resposta ainda não conclusiva.

Substantivo masculino - expressão concisa, fácil de lembrar, utilizada em campanhas políticas, de publicidade, de propaganda, para lançar um produto, marca etc. 
No marketing educacional e na comunicação para o mercado, essa preocupação com a qualidade de ensino parece ficar restrita apenas às propagandas, sejam impressas, televisivas, audiovisuais e em todas as redes sociais existentes, a qualidade é um fator apenas anunciado, não verificado, ela representa uma "ideia", que precisa ser vendida.

Creio seja importante esclarecer que o presente trabalho teve como objeto de análise duas vertentes, uma de cunho social, que representa o efeito da política neoliberal na educação como um facilitadora para que especialmente em nível superior de ensino grandes corporações assumissem o papel do Estado em prover vagas para alunos, cuja formação superior representa de forma direta uma possibilidade de ascensão social, e a outra de demonstrar como essas corporações utilizaram-se de agências especializadas em vendas para conquistar um número cada vez maior de pagantes por um ensino de terceiro grau.

No marketing educacional, questões relativas à qualidade do ensino, qualificação do corpo docente, instalações físicas, e todas as características que uma IES possui, são apenas de interesse para elaboração de materiais para propaganda. Como descrito anteriormente, em primeiro lugar para o aluno estudante e em segundo lugar para o aluno futuro.

Para as agências de publicidade o importante é alcançar seus objetivos, e aqui podemos dizer, explícitos, que se traduzem na conquista do aluno. Como uma "rede lançada", metáfora utilizada no mercado comunicacional, que representa a soma de esforços entre membros das corporações como gestores, áreas de marketing, comunicação e demais envolvidos que ajudam a compor de forma favorável os resultados positivos, isso fica evidente quando (Barbosa, 2011, p.317) destaca:

Os melhores resultados foram sempre obtidos quando uma rede foi armada antes, quando sentam na mesma sala, mantenedor, gestor de marketing ou comunicação, pró-reitores de graduação, pessoas da área financeira, coordenadores de curso, agência e assessoria de imprensa. Todos possuem o mesmo objetivo, alinham o mesmo pensamento e principalmente a tomada de decisão. Quando essa rede arma-se, os resultados são da IES. 


\section{CONSIDERAÇões Finais}

A intenção do presente trabalho teve como objetivo examinar e apresentar os efeitos negativos provocados por uma política neoliberal, especificamente na educação do ensino superior, representada por um "afastamento" do Estado em relação às suas responsabilidades legais/constitucionais e como essa política facilitou o crescimento de instituições de ensino privado no Brasil, uma vez que, com a adoção desse sistema, o Estado possibilitou a esses grupos assumirem as atribuições que eram em princípio do poder público. Embora tenhamos ciência de que ela tenha também surtido efeitos em outras as áreas sociais.

Importante salientar que em certos aspectos relacionados a educação, temos que reconhecer que de fato houve nesse contexto a real possibilidade de acesso ao ensino superior para uma camada significativa da população, não há aqui a intenção de assumir uma postura negacionista e sim demonstrar um dos aspectos resultantes de relação de causa e efeito estabelecidas entre IES e agências especializadas em marketing educacional, a qual foi propiciada pelo neoliberalismo.

O destaque permaneceu na observação dos mecanismos utilizados pelas IES na conquista desses alunos, apresentar algumas de suas estratégias e táticas, as quais poderíamos até mesmo percebê-las como agressivas, mas, conscientes de que este trabalho ainda careceu de uma análise efetiva sobre quais os resultados em relação à qualidade do ensino poderíamos perceber sendo consideradas nessa relação.

Nos textos utilizados como referência na presente análise, destacados no início, não surgiu nenhum aspecto relacionado à qualidade do ensino, ou que a qualidade fosse o principal item a ser evidenciado aos alunos atuais e aos futuros alunos nas ações da comunicação e marketing, tal qual análise feita por Mendonça Neto, Vieira e Antunes (2018).

Na busca por este "cliente" ficou evidente que a mais importante preocupação guarda estreita relação com a conquista desse aluno, em seguida, sua efetiva matrícula, e final e principalmente a permanência na IES. 
A qualidade do ensino fica subjacente e de forma também subliminar nos meios de comunicação já apresentados, demonstrando ser a qualidade por parte das agências um aspecto secundário em relação aos "serviços" oferecidos.

A Gestão e Financiamento da Educação, possibilita reflexão em um universo complexo, e dentro desse universo, destacamos aqui uma questão delicada, mas de extrema relevância: a atuação dos gestores especificamente dirigidas a manutenção e funcionamento das IES no âmbito privado.

Sabemos que para atingir esses objetivos são necessários recursos financeiros, os quais derivam das mensalidades recebidas dos alunos, e para que os esses escolham a IES são necessárias decisões e ações por parte da gestão que em parceria com agências especializadas em comunicação e marketing educacional fazem tudo o que for possível para conquistar esse cliente.

Não cabe aqui juízo de valores, as regras do jogo são claras, acredito que para nós pesquisadores da educação, compreender de forma mais aprofundada os meandros de uma gestão em ambiente acadêmico seja um dos aspectos mais importantes.

Não podemos negar a realidade educacional vivida no presente momento, pois acredito que somente conhecendo-a poderemos propor mudanças e quem sabe alcançar melhores resultados.

Todos nós que atuamos na educação poderemos em nossa vida, em alguma circunstância assumir o papel de gestor, e para cumprir com êxito essa tarefa árdua precisamos compreender o papel que a ele é designado.

Para o bem e para o mal, as agências publicitárias especializadas em marketing educacional cumprem a função que lhes cabem e não podemos negar, cumprem de forma efetiva e eficaz como inegavelmente deve ser. 


\section{REFERÊNCIAS}

BARBOSA, Tório. Comunicação para o mercado educacional. In. COLOMBO, Rodrigues e Colaboradores. Desafios da gestão universitária contemporânea. Porto Alegre: Artmed, 2011, p.301-318.

NUNES. Mekler Nichele. Dos passos estratégicos aos caminhos do marketing educacional. In. COLOMBO, S.S. (org). Gestão universitária: os caminhos para excelência. Porto Alegre: Artmed, 2014, p.263-279.

LAVAL. Christian. A escola não é uma empresa: o neoliberalismo em ataque ao ensino público. tradução Maria Echalar. 1.ed, São Paulo: Boitempo, 2011.

MENDONÇA NETO, O. R.; VIEIRA, A. M.; ANTUNES, M. T. P. Industrialização da educação, edtech e prática docente. Eccos Revista Científica, v. 3, p. 149-170, 2018.

TAVARES. Sérgio Marcus Nogueira. As universidades confessionais brasileiras e as reformas da educação superior da década de 1990. Tese de Doutorado. São Carlos:UFSCar, 2012, 260 f.

Recebido em: 23-7-2021

Aprovado em: 2-12-2021

Avaliado pelo sistema double blind review.

Disponível em http://mjs.metodista.br/index.php/roc 